\title{
Herbivore-induced maize leaf volatiles affect attraction and feeding behavior of Spodoptera littoralis caterpillars
}

\author{
Georg E. von Mérey, Nathalie Veyrat, Marco D'Alessandro and Ted C. J. Turlings* \\ Laboratory for Fundamental and Applied Research in Chemical Ecology, Institute of Biology, University of Neuchâtel, Neuchâtel, Switzerland
}

\section{Edited by:}

Marcel Dicke, Wageningen

University, Netherlands

Reviewed by:

Anne M. Cortesero, University of

Rennes 1, France

James Blande, University of Eastern

Finland, Finland

*Correspondence:

Ted C. J. Turlings, Laboratory for

Fundamental and Applied Research

in Chemical Ecology, Institute of

Biology, University of Neuchâtel,

Emile-Argand 11, C.P. 158,

CH-2009 Neuchâtel, Switzerland

e-mail: ted.turlings@unine.ch

\begin{abstract}
Plants under herbivore attack emit volatile organic compounds (VOCs) that can serve as foraging cues for natural enemies. Adult females of Lepidoptera, when foraging for host plants to deposit eggs, are commonly repelled by herbivore-induced VOCs, probably to avoid competition and natural enemies. Their larval stages, on the other hand, have been shown to be attracted to inducible VOCs. We speculate that this contradicting behavior of lepidopteran larvae is due to a need to quickly find a new suitable host plant if they have fallen to the ground. However, once they are on a plant they might avoid the sites with fresh damage to limit competition and risk of cannibalism by conspecifics, as well as exposure to natural enemies. To test this we studied the effect of herbivore-induced VOCs on the attraction of larvae of the moth Spodoptera littoralis and on their feeding behavior. The experiments further considered the importance of previous feeding experience on the responses of the larvae. It was confirmed that herbivore-induced VOCs emitted by maize plants are attractive to the larvae, but exposure to the volatiles decreased the growth rate of caterpillars at early developmental stages. Larvae that had fed on maize previously were more attracted by VOCs of induced maize than larvae that had fed on artificial diet. At relatively high concentrations synthetic green leaf volatiles, indicative of fresh damage, also negatively affected the growth rate of caterpillars, but not at low concentrations. In all cases, feeding by the later stages of the larvae was not affected by the VOCs. The results are discussed in the context of larval foraging behavior under natural conditions, where there may be a trade-off between using available host plant signals and avoiding competitors and natural enemies.
\end{abstract}

Keywords: Spodoptera littoralis, green leaf volatiles, maize, larval foraging behavior, host plant suitability

\section{INTRODUCTION}

Maize plants attacked by herbivorous insects emit volatile organic compounds (VOCs) that attract natural enemies of herbivores (Dicke et al., 1990; Turlings et al., 1990; Turlings and Wäckers, 2004; Arimura et al., 2009). In the case of maize plants, the blend of VOCs emitted by caterpillar-damaged plants is typically composed of green leaf volatiles (GLVs, C-6 aldehydes, alcohols, and their esters), nitrogenous, and aromatic compounds, as well as mono, homo and sesquiterpenes (Paré and Tumlinson, 1999; D'Alessandro and Turlings, 2006). Among the VOCs that have been identified in these blends, GLVs have received particular attention. They are emitted upon mechanical damage, immediately after feeding on the maize plant begins (Turlings et al., 1998), and have been considered important for the innate attraction of parasitoids, as they are emitted in higher amounts by freshly damaged plants than by plants with only old damage (Whitman and Eller, 1990; Hoballah and Turlings, 2005). Commonly, insect herbivores are repelled by inducible plant volatiles (Bernasconi et al., 1998; De Moraes et al., 2001; Rostas and Hilker, 2002). This is particularly evident for Lepidoptera (De Moraes et al., 2001), but this is not true for all herbivores. In particular coleopterans are known to be attracted to previously infested plants (Bolter et al., 1997; Landolt et al., 1999) and they may be attracted to GLVs as was found for scarab (Hansson et al., 1999) and buprestid beetles (de Groot et al., 2008), and flea beetles (Halitschke et al., 2008).

Interestingly, larval stages of several Lepidoptera are attracted by volatiles emitted by plants that have been damaged by conspecific larvae. This was found for neonates of several Lepidoptera species, including Ostrinia nubialis (Hübner) and Ostrinia furnacalis (Guenée) (Lepidoptera: Pyralidae) on maize (Huang et al., 2009; Piesik et al., 2009), Spodoptera frugiperda (J. E. Smith) (Lepidoptera: Noctuidae) on maize and cowpea (Carroll et al., 2006, 2008), and Estigmene acrea (Drury) (Lepidoptera: Arctiidae) on soybean, tomato, and maize (Castrejon et al., 2009). Furthermore, caterpillars adapt their behavior depending on plant VOC emission (Shiojiri et al., 2006). This attraction to VOCs emitted by already infested host plants is puzzling, as it will lead to competition and may increase the risk of cannibalism and attack by natural enemies that are attracted to the same volatiles. Cannibalism is common among noctuid larvae, such as Spodoptera littoralis (Boisduval) (Abdel Salam and Fokhar. cited in Fox, 1975), S. frugiperda (Chapman et al., 1999), and Helicoverpa armigera (Hübner) (Kakimoto et al., 2009). The attraction of natural enemies to herbivore-induced volatiles has been shown for numerous tritrophic systems (Dicke 
et al., 1990; Turlings et al., 1990; Heil, 2008; Dicke and Baldwin, 2010; Hare, 2011), which makes one wonder why lepidopteran larvae are attracted to the same volatiles. This apparent maladaptive behavior may be explained by a trade-off between risks: in the field harsh weather conditions and attempts to escape parasitoids and predators cause larvae to frequently fall off plants (personal observ.). In order to find back the same plant or new suitable plants the larvae will have to rely on dependable and available VOC signals. Induced VOCs may provide the best cues, as undamaged plants are often virtually odorless (Turlings et al., 1990). However, once on a plant, caterpillars may prefer sites with minimal VOC emissions, where it is less likely to encounter competitors and natural enemies.

We therefore hypothesized that caterpillars may initially be attracted to induced VOCs, but once they are on the plant they will feed preferentially in places with low GLV emissions. We tested this for larvae of the noctuid moth Spodoptera littoralis (Boisduval). First we confirmed attraction to induced plant volatiles in a four-arm olfactometer and then tested their growth rate as a measure of feeding behavior when they were exposed to GLVs. Previous feeding experiences were also taken into consideration, as larval attraction may be higher for volatiles that are emitted by plant species on which the larvae previously fed (Carlsson et al., 1999).

\section{MATERIALS AND METHODS PLANTS AND INSECTS}

Maize plants (Zea mays, cv. Delprim) were grown individually in plastic pots $(10 \mathrm{~cm}$ high, $4 \mathrm{~cm}$ diameter) with commercial potting soil (Ricoter Aussaaterde, Aarberg, Switzerland) and placed in a climate chamber $\left(23^{\circ} \mathrm{C}, 60 \%\right.$ r.h., 16:8 h L:D, $50000 \mathrm{~lm} / \mathrm{m}^{2}$ ). Maize plants used for the experiments were 10-12 days old and had three fully developed leaves. The evening before the experiments, plants were transferred into glass vessels, as described in Turlings et al. (2004) and kept under laboratory conditions $\left(25 \pm 2^{\circ} \mathrm{C}, 40 \pm 10 \%\right.$ r.h., 16:8 h L:D, and $\left.8000 \mathrm{~lm} / \mathrm{m}^{2}\right)$. S. littoralis larvae were reared from eggs provided by Syngenta (Stein, Switzerland). The eggs were kept in an incubator at $30.0 \pm 0.5^{\circ} \mathrm{C}$ until emergence of the larvae. Subsequently, they were transferred on artificial diet at room temperature $\left(24 \pm 4^{\circ} \mathrm{C}\right)$.

\section{OLFACTOMETER EXPERIMENTS}

Two olfactometer experiments were performed with fourth-instar S. littoralis larvae. In the first experiment, the attraction of larvae to an $S$. littoralis-infested maize plant vs. healthy maize plant was compared. In the second experiment, the attraction of larvae to a maize plant with fresh (mechanically inflicted) damage was tested against a plant with old (mechanically inflicted) damage. In both experiments, the effect of previous feeding experience (either artificial diet or maize) was compared. All the larvae were initially reared on artificial diet as previously described (Turlings et al., 2004). Twenty-four hours before each experiment, 90 larvae were transferred on fresh maize leaves (maize feeding experience), and 90 on artificial diet (artificial diet feeding experience).

\section{ATTRACTION OF FOURTH-INSTAR $S$. littoralis LARVAE TO INFESTED MAIZE PLANTS}

A four-arm olfactometer (as described in D'Alessandro and Turlings, 2005) was modified to measure the attraction of $S$. littoralis larvae. The olfactometer consisted of a central glass choice arena (Figure 1) $[6 \mathrm{~cm}$ internal diameter (ID), $5 \mathrm{~cm}$ length] with four arms (15 mm ID, $5 \mathrm{~cm}$ length), each with a glass elbow $(5 \mathrm{~cm}$ length) and an upward connection for a glass bulb $(50 \mathrm{ml})$. To avoid visual distraction of the larvae, a white cardboard cylinder was placed around the central choice arena.

The choice arena was connected to four glass bottles. One bottle contained a maize plant (cv Delprim) infested with 15 second-instar $S$. littoralis larvae that had been placed on the plant $16 \mathrm{~h}$ before the bioassay. The opposite bottle contained a healthy maize plant. The two remaining bottles remained empty. The position of the odor sources was changed between each experimental day, with the two odor sources always opposite to each other.

Thirty fourth-instar larvae were placed in a small plastic box $(2 \times 2 \times 0.8 \mathrm{~cm})$ with an open top, which was introduced in the center of the choice arena. The larvae would crawl out of the box into the central choice arena and a number of them entered one of the four arms. After $60 \mathrm{~min}$, the number of larvae in each arm was counted. The larvae that did not leave the choice arena after 60 min were considered as having made "no choice" and all the larvae were removed from the olfactometer. Six such releases were done on a given day and this was repeated on 6 different days $(n=6)$.

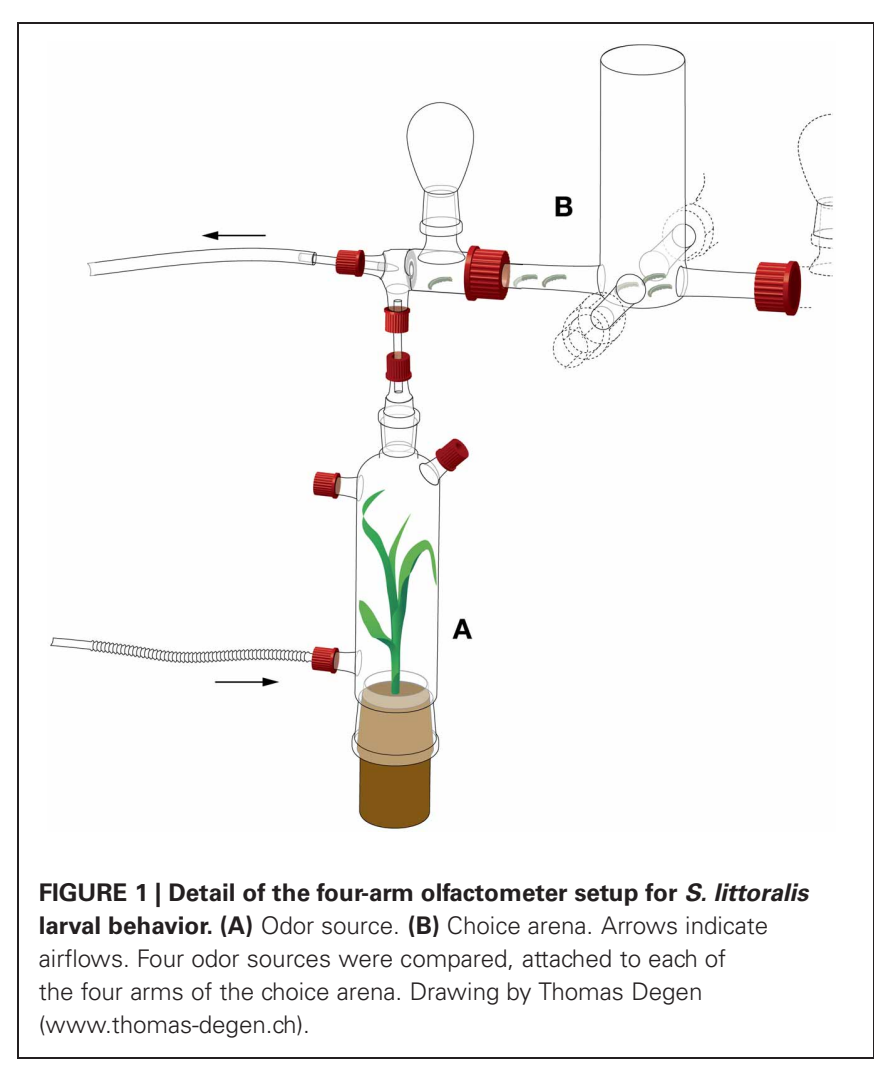




\section{ATTRACTION OF FOURTH-INSTAR $S$. littoralis LARVAE TO PLANTS WITH OLD vs. PLANTS WITH FRESH DAMAGE}

The same setup as described above was used, with the same experimental procedure, except for the odor sources. Two maize plants were brought to the laboratory $16 \mathrm{~h}$ prior to the bioassay. One plant was scratched on the underside of the two oldest leaves, damaging approximately $2 \mathrm{~cm}^{2}$, on both sides of the central vein (Hoballah and Turlings, 2005). Caterpillar regurgitant, collected as described in Turlings et al. (1998), was applied to the two wounds. Both plants were then placed in a glass bottle and exposed to a carbon-filtered, humidified airflow of $300 \mathrm{ml} / \mathrm{min}$ for $15 \mathrm{~h}$. The second plant was then scratched and regurgitant was applied. The two plants were then placed opposite to each other in the olfactometer, leaving two empty bottles between them. The airflow was then increased to $1200 \mathrm{ml} / \mathrm{min}$ through each bottle, of which $500 \mathrm{ml} / \mathrm{min}$ entered the olfactometer choice chamber. The position of the treatments was changed for each experimental day.

\section{GLV DISPENSERS}

To expose larvae to green leafy volatiles we made dispensers as described by von Mérey et al. (2011). The GLVs were first mixed together in an Erlenmeyer flask $(100 \mathrm{~mL})$ placed in ice. The composition of the mixture was $80 \%$ cis-3-hexen-1-al [ $92.5 \%$ purity, (NEAT), Bedoukian Research Inc., USA]; 10\% cis-3-hexen-1ol (>98\%, GC, Sigma-Aldrich, CH-9471 Buchs, Switzerland); $8 \%$ cis-3-hexenyl acetate (>98\%, SAFC Supply Solutions, 3050 Spruce street, St. Louis, MO 63103, USA); and 2\% trans-2hexenol (99\%, ACROS Organics, New Jersey, USA). The mix was stored at $-70^{\circ} \mathrm{C}$ until it was used. For the assays, $0.2 \mathrm{~mL}$ of the GLV mix was transferred into a $2 \mathrm{~mL}$ amber glass vial $(11.6 \times 32 \mathrm{~mm})$ (Sigma-Aldrich, CH-9471 Buchs, Switzerland) containing clean fiberglass wool. Each vial was sealed with a PTFE/rubber septum pierced by a Drummond $2 \mu \mathrm{L}$ micropipette in black polypropylene cap. This device allowed the constant release of GLVs, and their release rate was calibrated to the amount of GLVs that was found to be released by infested maize plants (Zea mays cv Delprim) (von Mérey et al., 2011). Control dispensers consisted of glass vials only containing fiberglass wool.

\section{VOC-EXPOSURE EXPERIMENTS}

Three experiments were conducted to measure the effect of VOCs on the growth of $S$. littoralis larvae. In the first experiment, the larvae were exposed to the volatiles of caterpillar-damaged maize plants. In the second experiment, they were exposed to amounts of a blend of synthetic GLVs that fall within the range of what is commonly emitted by a single, caterpillar-infested maize plant (see von Mérey et al., 2011 for details). In the third experiment, they were exposed to high concentrations of synthetic GLVs. In all three experiments we recorded, besides weight gain, mortality, and pupation of the larvae.

\section{EFFECT OF EXPOSURE TO VOCs EMITTED BY CATERPILLAR-DAMAGED MAIZE PLANTS ON FEEDING RATE OF S. littoralis LARVAE}

Second-instar $S$. littoralis were placed individually inside small plastic boxes $(2 \times 2 \times 1.5 \mathrm{~cm})$ that were covered with

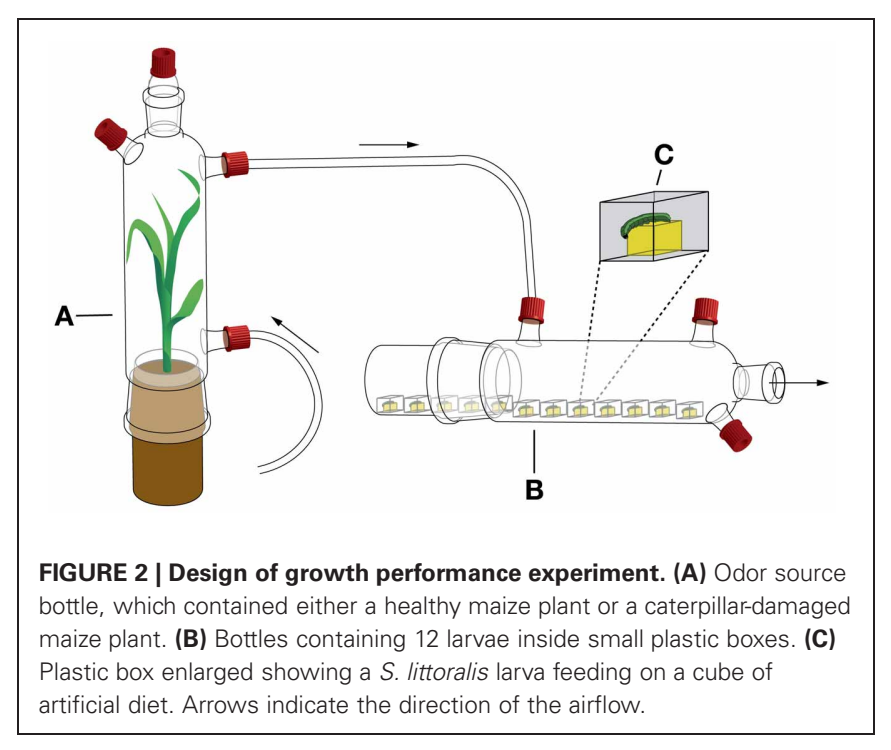

fine-meshed nylon tissue, fixed with an elastic band. The larvae were provided a $1 \mathrm{~cm}^{3}$ cube of wheatgerm-based artificial diet (Turlings et al., 2004), which was changed every second day. Twelve such boxes were placed inside a glass bottle lying on its side, connected at its base with a Teflon tube to the top of an odor source bottle (Figure 2; see Turlings et al., 2004 for details on glass bottles and tubing). Odor source bottles contained either a maize plant infested with fifteen second-instar S. littoralis larvae (induced plant, VOCi, replaced with a new infested plant every third day) or an uninfested maize plant (control plant, VOCu, also replaced every third day). The odor source bottle was connected to a four-port air-delivery system (Model VCS-HADS-6AF6C6B; ARS Analytical Research Systems, Gainesville, FL, USA), providing a purified and humidified airflow of $300 \mathrm{ml} / \mathrm{min}$. Two such four-port air-delivery systems were used simultaneously to introduce odors into eight exposure chambers, resulting in 48 larvae for each treatment.

Before placing the larvae inside the plastic boxes, they were weighed on a microbalance (Model MX5, Mettler Toledo, Greifensee, Switzerland). Weighing was repeated at the following time-points after placing the boxes inside the glass bottle: 5, 24, $48,96,144,192,240,288,312,336,360,408$, and $432 \mathrm{~h}$. After this time-point, all larvae had pupated or had died and the experiment was terminated.

\section{EFFECT OF EXPOSURE TO SYNTHETIC GLVS ON WEIGHT GAIN OF S. littoralis LARVAE}

The same setup as described above was used for this experiment. In this case, the odor source bottles containing a dispenser built up as follows: a $2 \mathrm{ml}$ amber glass vial $(11.6 \times$ $32 \mathrm{~mm}$; Sigma-Aldrich, Buchs, Switzerland) containing $100 \mathrm{mg}$ clean fiberglass wool. The vial was sealed with a PTFE/rubber septum (Sigma-Aldrich, Buchs, Switzerland) pierced with a $2 \mu l$ micro-pipette (Drummond, Millan SA, Plan-Les-Ouates, Switzerland). The length of the pipette was calibrated to release a controlled amount of GLVs, similar to the amount emitted by maize plants (cv Delprim). The GLV mixture consisted of $80 \%$ 
(Z)-3-hexen-1-al [92.5\% purity, (NEAT), Bedoukian Research, Danbury, CT, USA], 10\% (Z)-3-hexenyl-acetate (<98\%, SAFC Supply Solutions, St. Louis, MO, USA), 8\% (Z)-3-hexenylAcetate ( $\geq 98 \%$, SAFC Supply Solutions, 3050 Spruce Street, St. Louis, MO 63103, USA), and 2\% (E)-2-hexenol (99\%, ACROS Organics, Geel, Belgium). The same GLV dispenser was kept for the duration of the assay. Control bottles contained no dispenser.

In this experiment, the weighing of the larvae was repeated at $5,12,24,48,96,120$, and $144 \mathrm{~h}$ after placement in the bottles. The experiment was terminated at $144 \mathrm{~h}$ because the tests showed that larval weight was not affected by the volatiles at these concentrations.

\section{EFFECT OF EXPOSURE TO HIGH CONCENTRATIONS OF GLVs ON WEIGHT GAIN OF S. littoralis LARVAE}

In this experiment, larvae were placed individually in a plastic box $(7.5 \times 6.5 \times 5 \mathrm{~cm})$ containing a GLV dispenser (described above), and a piece of diet $(2 \times 1.5 \times 1 \mathrm{~cm})$. The box was closed, in order to increase the concentration of GLVs. As a control, an empty dispenser was placed inside the cage without GLVs inside. There were twelve larvae in each treatment and they were weighed before placing them inside the boxes. They were weighed again after $3,6,9,12,15,24,40,48,51,54,58,72,96,120$, and $168 \mathrm{~h}$.

The larger plastic boxes allowed for more mobility, compared to the cages used in the previous experiments. In order to observe whether the high concentrations of GLV affected larval mobility, we recorded whether the larvae were on the diet or off the diet during the first $8 \mathrm{~h}$ of exposure.

\section{STATISTICAL ANALYSIS}

VOC-exposure data were compared using Student's $t$-test, provided they met the assumptions of normality (Shapiro-Wilk test) and equal variance (Levene's test). Else, a Mann-Whitney test was applied. Both treatments (VOCu and VOCi exposure) were compared at each time-point individually. Data on mortality and pupation of the larvae compared using a one-way analysis of variance (ANOVA). Data was tested with SigmaStat (version 3.5, STATCON, Witzenhausen, Germany). Data on mobility were analyzed in a general linear model (GLM) with binomial distribution (the larvae were observed either on the diet or off the diet) family in $\mathrm{R}$ ( $\mathrm{R}$ Development Core Team, 2009). Olfactometer data was analyzed using the software package R ( $\mathrm{R}$ Development Core Team, 2009), in a GLM, allowing to compensate for over-dispersed data, as previously described (D’Alessandro and Turlings, 2005; Tamò et al., 2006; Ricard and Davison, 2007). This means that any positional biases or effects of the individuals on each other's behavior are considered in the model and that calculated statistical differences are solely the result of differential attractiveness of the odor sources.

\section{RESULTS}

\section{ATTRACTION OF FOURTH-INSTAR $S$. littoralis LARVAE TO INDUCED MAIZE PLANTS}

The larvae that had fed on maize and the larvae fed on artificial diet were both more attracted toward caterpillar-damaged maize plants than to intact plants (GLM $P<0.001$ and $P<$ 0.002, respectively; Figure 3). However, the maize-fed larvae were attracted more strongly by the induced plants than the diet-fed

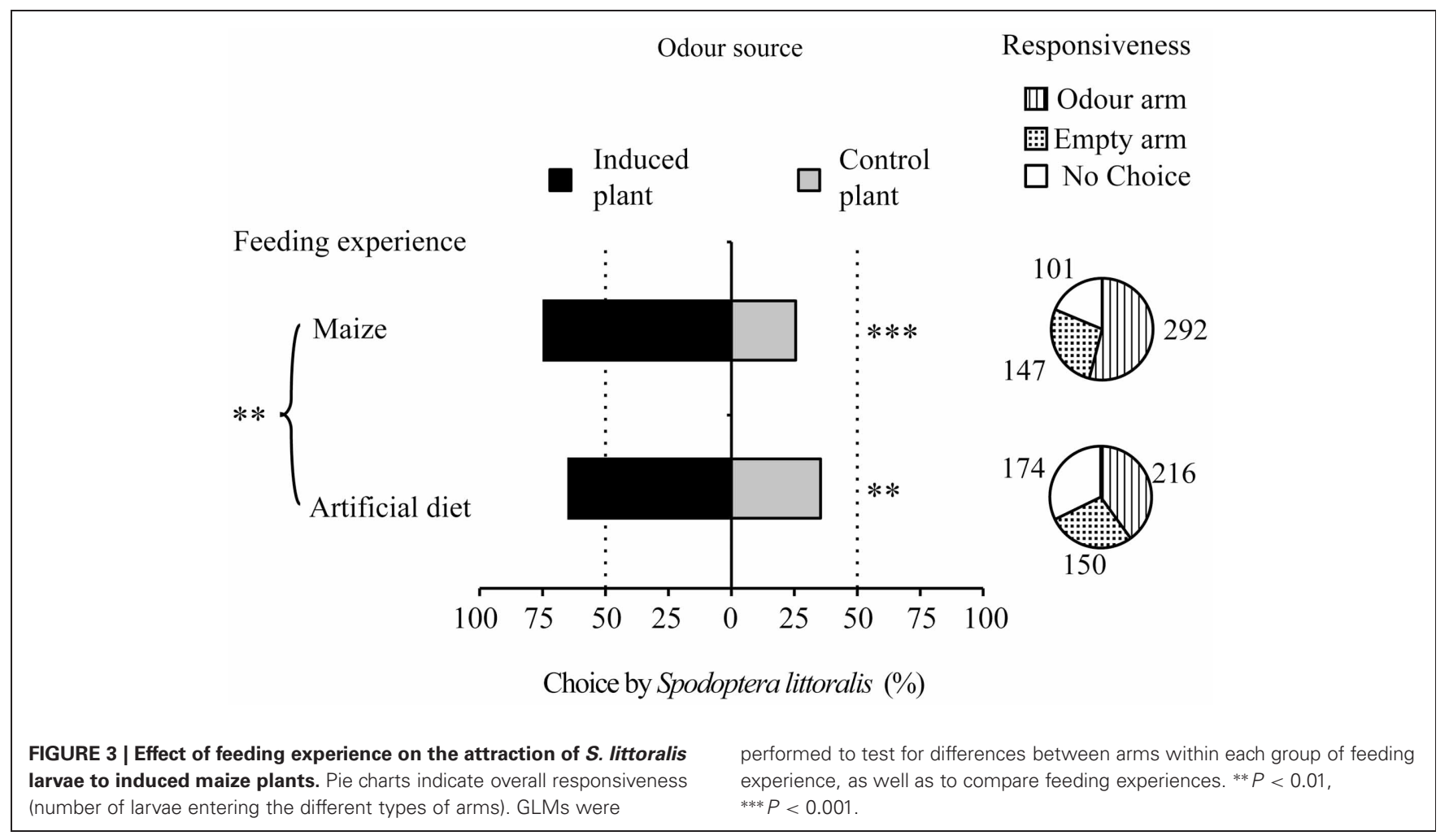




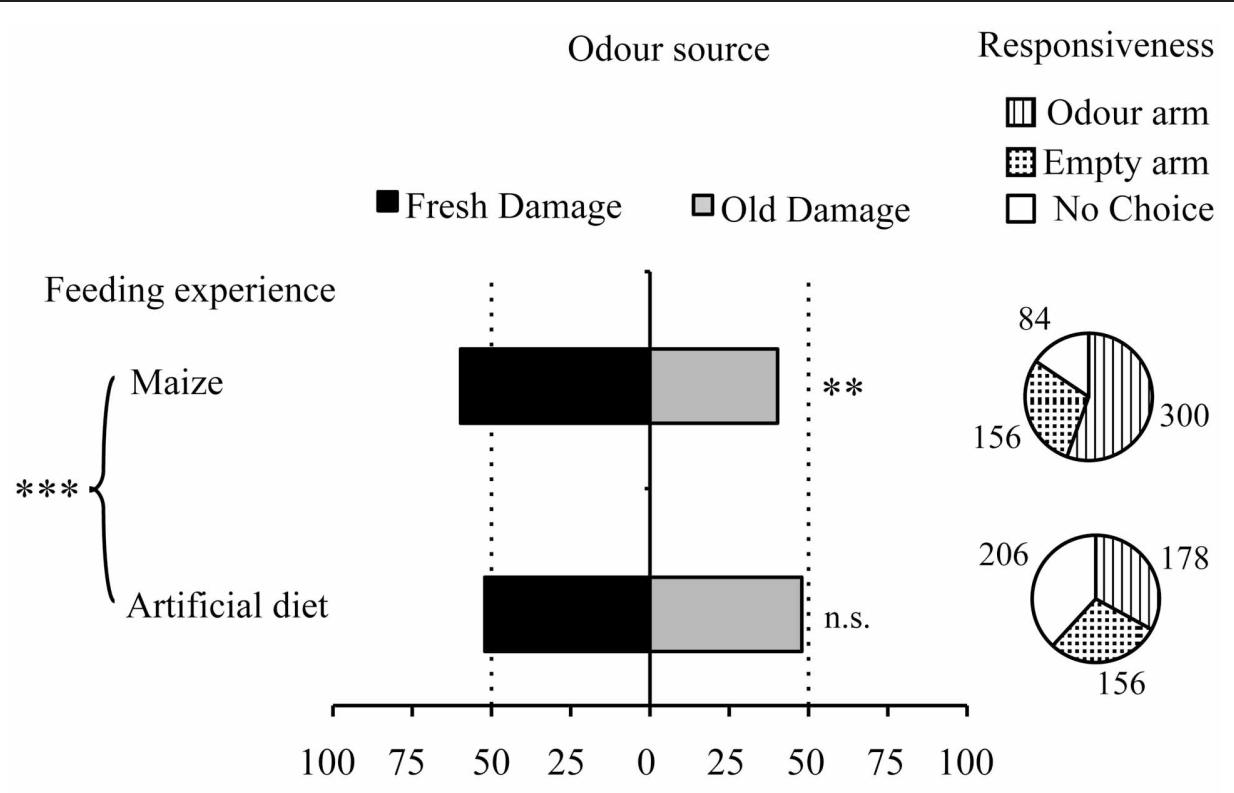

Choice by Spodoptera littoralis (\%)

FIGURE 4 | Effect of feeding experience on the attraction of $S$. littoralis larvae to old and fresh damaged maize plants. Pie charts indicate overall responsiveness (number of larvae entering the different types of arms).
GLMs were performed to test for differences between arms within each group of feeding experience, as well as to compare feeding experiences. n.s., no significant difference $(P>0.05) ;{ }^{* *} P<0.01,{ }^{* * *} P<0.001$. larvae (GLM $P<0.005$ ). Maize-fed larvae also displayed an increased responsiveness ( $80 \%$ entering an arm) compared to diet-fed larvae (66\%).

\section{ATTRACTION TO OLD vs. FRESH DAMAGE}

Freshly damaged plants were more attractive to maize-fed larvae (GLM $P<0.003)$ than plants with older damage (Figure 4). Artificial diet-fed larvae did not show a preference between old and fresh damage. This difference in preference between maize-fed and diet-fed larvae was significant (GLM $P<0.001$ ). Also in this case, overall responsiveness of maize-fed larvae (84\%) was higher than the responsiveness of artificial diet-fed larvae $(62 \%)$.

\section{EXPOSURE TO VOCS FROM CATERPILLAR-DAMAGED MAIZE PLANTS}

The larvae that were exposed to the VOCs emitted by caterpillardamaged maize plants grew more slowly in the early stages of development (Figure 5). Initial weight of the larvae was equal across treatments. After $5 \mathrm{~h}$, there was still no difference between the two treatment groups $(P<0.356)$. However, after $24 \mathrm{~h}$, the larvae exposed to VOCs from damaged plants (VOCi) had gained significantly less weight than the larvae exposed to VOCs emitted by healthy plants (VOCu) $(P<0.030)$. This difference in growth rate persisted throughout the early weighing time points: $48 \mathrm{~h}$ $(P<0.030), 96 \mathrm{~h}(P<0.012), 144 \mathrm{~h}(P<0.033)$. After this, both treatment groups displayed similar weight gains until pupation. The weight of the pupae did not differ significantly $(P<0.916)$. There was also no difference in mortality between the larvae of the two treatment groups $(P<0.839)$.

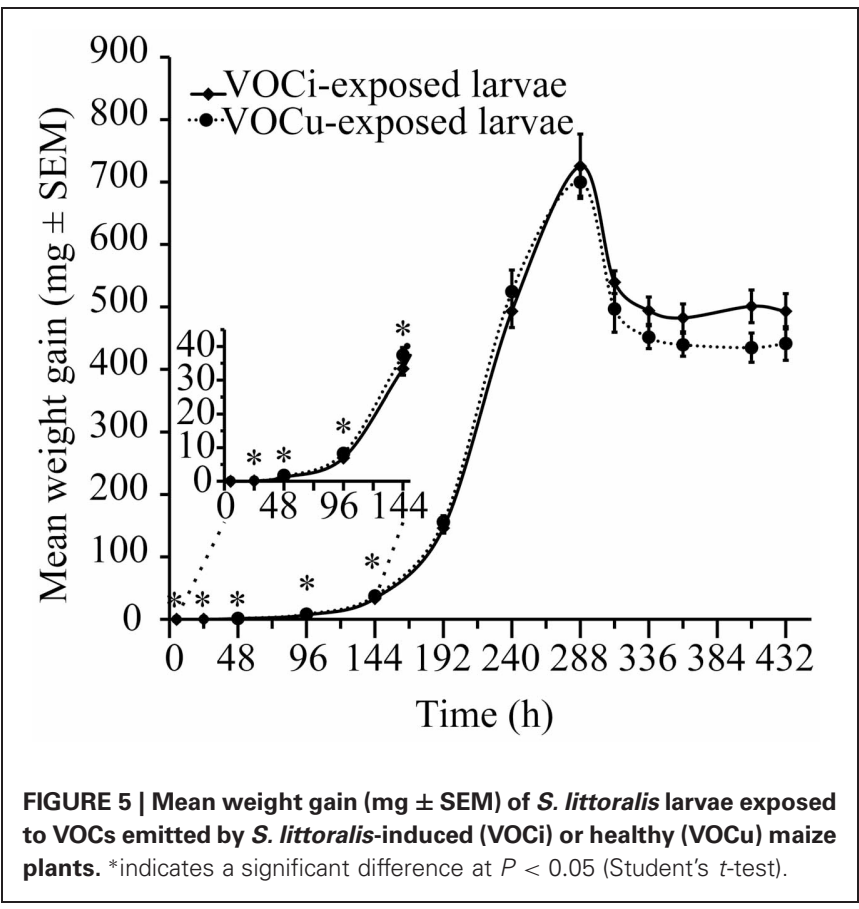

EFFECT OF EXPOSURE TO LOW CONCENTRATIONS OF SYNTHETIC GLVS ON WEIGHT GAIN OF S. littoralis LARVAE

When larvae were exposed to the synthetic volatile blend we measured no difference either in larval weight gain $(5 \mathrm{~h}: P<0.759$, 


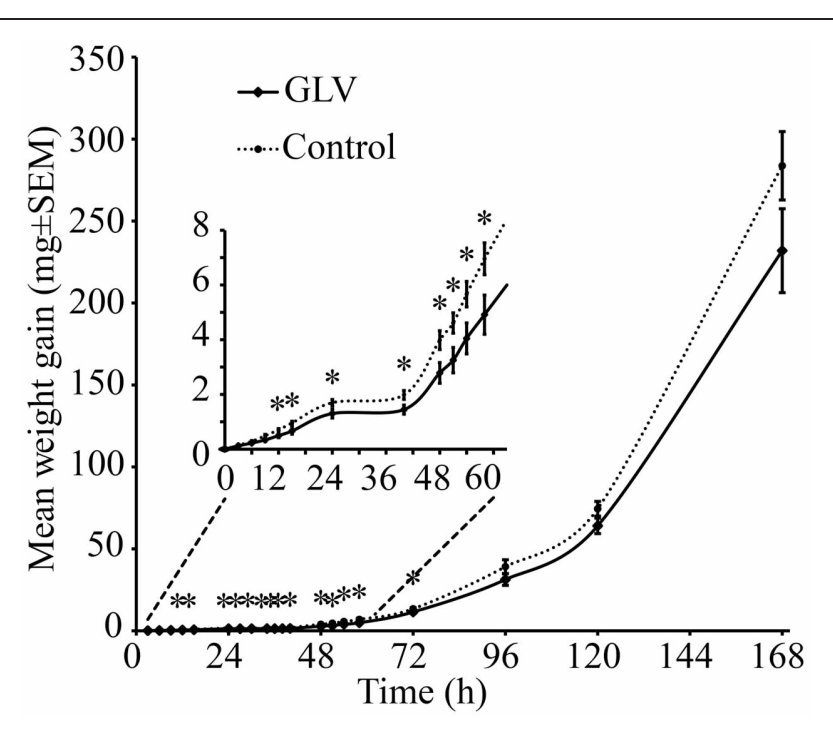

FIGURE 6 | Weight gain ( $\mathrm{mg} \pm \mathrm{SEM}$ ) of $S$. littoralis larvae exposed to GLV dispensers or control dispensers. An asterisk above the value point indicates significant difference between treatments $(P<0.05$ Student's $t$-test).

12 h: $P<0.286,24$ h: $P<0.267,48$ h: $P<0.502,72$ h: $P<$ 0.506, 96 h: $P<0.833,120$ h: $P<0.833,144$ h: $P<0.646)$, or mortality ( $0 \%$ in both treatments).

\section{EFFECT OF EXPOSURE TO HIGH CONCENTRATIONS OF GLVS ON WEIGHT GAIN OF S. littoralis LARVAE}

When larvae were exposed to high concentrations of GLVs, such as can be expected to be present in the immediacy of the feeding sites on the maize plants, the larvae were found to gain less weight at the early stages of their development (Figure 6). After $3 \mathrm{~h}(P<0.514)$ and $6 \mathrm{~h}(P<0.173)$, there was still no difference between the treatments. After exposure to GLVs for $9 \mathrm{~h}$ a strong trend of lower weight gain in GLV-exposed larvae was observed $(P<0.051)$ and at $12 \mathrm{~h}$ the difference between the two treatments was significant $(P<0.025)$. This difference persisted throughout the early part of the experimental time $(15 \mathrm{~h}$ : $P<0.036$; 24h: $P<0.027$; 40 h: $P<0.031$; 48 h: $P<0.030$; 51 h: $P<0.033$; 54 h: $P<0.039$; 58 h: $P<0.038$; 72 h: $P<$ 0.047). From $96 \mathrm{~h}$, however, there was no longer a difference in weight gain between the treatments. Interestingly, the mobility of GLV-exposed larvae was slightly increased $(P<0.060)$, with a significant difference in number of larvae moving in the box after $6 \mathrm{~h}(P<0.048)$. However, at $30 \mathrm{~min}(P<0.410)$, $2 \mathrm{~h}(P<0.716)$, $4 \mathrm{~h}(P<0.572)$, and $8 \mathrm{~h}(P<0.423)$, GLVexposed and control larvae were equally on the diet and off the diet.

\section{DISCUSSION}

We show here that Spodoptera littoralis caterpillars are attracted to volatiles from maize plants that are under attack by conspecifics. This confirms the findings by Carroll et al. (2006, 2008), who obtained similar results for a related species, S. frugiperda, which was found to be attracted to inducible volatiles emitted from maize and cowpea seedlings. Similarly, neonate larvae of the codling moth, Cydia pomonella, are more attracted to apple fruits with other codling moth larvae than to uninfested fruits (Landolt et al., 2000). This is somewhat surprising, as these Lepidoptera are not known to aggregate, unlike many Coleoptera, for which both adults and larvae are often attracted to the volatiles of already infested plants (Crowe, 1995; Bolter et al., 1997; Müller and Hilker, 2000; Kalberer et al., 2001; Heil, 2004; Yoneya et al., 2010). It should be noted that in the case of $S$. frugiperda, Carroll et al. (2008) found linalool to be particularly attractive. This terpene alcohol is in fact also released, be it in lesser amounts, by undamaged maize plants, at least in some varieties (Degen et al., 2004), and therefore can be a reliable cue for the presence of maize in general. In adult Lepidoptera, however, increased linalool levels decreased oviposition (De Moraes et al., 2001; Kessler and Baldwin, 2001).

The larval response to herbivore-induced volatiles is in contrast to what is known for adult Lepidoptera, which avoid to oviposit on plants that are already under caterpillar attack (Landolt, 1993; De Moraes et al., 2001; Kessler and Baldwin, 2001; Huang et al., 2009). Such avoidance of already infested plants, which is also the case for aphids (Bernasconi et al., 1998), is expected, as it reduces the chances of competition and cannibalism, as well as predation and parasitism by natural enemies that are attracted to the same volatiles. Then why are the larvae attracted to volatiles that are indicative of these risks? To answer this it may help to list the potential disadvantages and discuss counter arguments why these may not be as important as potential advantages. The apparent disadvantages are: (1) VOCs emitting plants have mobilized their defenses and should be less suitable for caterpillar development, (2) The VOCs indicate the plants carry other larvae that will compete for the same resource and may even pose a cannibalism risk, (3) The VOCs are attractive to natural enemies of the caterpillars and therefore indicate a higher risk of predation and parasitism.

As for the counter argument, the most obvious reason to use herbivore-induced VOCs is the same as has been argued for the natural enemies (Vet and Dicke, 1992), the induced VOCs are emitted in large amounts and are therefore easily detectible and reliable cues for the presence of a host plant. Moreover, the alternative, the avoidance of inducible defenses by opting for healthy plants gives only an advantage for a very short period of time, as maize plants respond very rapidly, within hours, to an attack (Turlings et al., 1998). This is particularly true for plants that are neighboring already attacked plants and have their defenses primed in response to the volatiles emitted by the neighbor (Ton et al., 2007). This then only leaves the risk of competition and possibly cannibalism. This risk may be minor in light of the possibility of not finding a plant at all and unlike $S$. frugiperda, S. littoralis is not cannibalistic, at least not the colony that we used in our experiments. We therefore hypothesized that Spodoptera and other larvae of herbivorous insects have adapted to use the readily available and reliable herbivore-induced volatile signals to find host plants despite the risks they will face on these plants, because the likely alternative would be starvation. A similar argument formulated by Carroll et al. (2006) emphasizes the limited range at which caterpillars can forage, as compared to the highly mobile 
adults. The far less mobile caterpillars, when fallen to the ground, have a high risk of predation and are fully exposed to unfavorable environmental conditions. Getting back on a plant should be high priority and in most cases the same plant will be the closest to crawl on. This may also explain why we found that a previous feeding experience has a significant impact on the attractiveness of the induced maize volatiles. Similar preferences for familiar odors in S. littoralis larvae were found by Anderson et al. (1995) and Carlsson et al. (1999) when they studied the caterpillar's responses to cotton volatiles. This effect of experience even extends to the adult moth, which prefers to oviposit on the same plant species on which it fed as a larva (Anderson et al., 1995). It is also known that caterpillars adapt their feeding physiology to plant diet on which they feed as neonates and will perform worse on an alternative diet (del Campo et al., 2001; Zalucki et al., 2002), the more reason for the larvae to forage for the same plant species.

Once on an already infested plant, however, caterpillars could lessen the risks of competition/cannibalism, which can be very severe in certain Spodoptera species (Chapman et al., 1999, 2000; Richardson et al., 2009), but this is not the case for S. littoralis. They will also reduce the risk of predation and parasitism by avoiding the most odorous plant parts (Turlings and Wäckers, 2004). This notion is tentatively supported by the effects of maize VOCs on caterpillar feeding behavior. S. littoralis larvae that were exposed to the VOCs induced by their conspecifics on maize plants were found to feed and grow less than larvae that were not exposed to the VOCs (Figure 3). This is indicative of an avoidance of the VOCs, which was only evident at high concentrations. Hence, the results of the current study support our hypothesis that on a plant the caterpillars prefer to commence feeding away from freshly damaged areas, i.e., sites from which large amounts of GLVs are emitted. Yet, alternative explanations should be considered. For instance, the larvae that were exposed

\section{REFERENCES}

Anderson, P., Hilker, M., and Löfqvist, J. (1995). Larval diet influence on oviposition behavior in Spodoptera littoralis. Entomol. Exp. Appl. 74, 71-82. doi: 10.1111/j.15707458.1995.tb01876.x

Arimura, G., Matsui, K., and Takabayashi, J. (2009). Chemical and molecular ecology of herbivoreinduced plant volatiles: proximate factors and their ultimate functions. Plant Cell Physiol. 50, 911-923. doi: 10.1093/pcp/pcp030

Bernasconi, M. L., Turlings, T. C. J., Ambrosetti, L., Bassetti, P., and Dorn, S. (1998). Herbivoreinduced emissions of maize volatiles repel the corn leaf aphid, shape Rhopalosiphum maidis. Entomol. Exp. Appl. 87, 133-142. doi: 10.1046/j.1570-7458.1998.00315.x

Bolter, C. J., Dicke, M., Van Loon, J. J. A., Visser, J. H., and Posthumus, M. A. (1997). Attraction of Colorado larvae to volatiles from herbivore-

to GLVs volatiles might have been attracted and searched for the source of the volatiles and therefore ate less on the diet that they were offered. We can also not exclude a direct (toxic) effect of the volatiles on the larvae.

In summary, we show here that Spodoptera littoralis larvae are attracted to the volatiles emitted by plants that are already damaged by conspecific larvae. Although such plants are less suitable for the larvae than undamaged plants, the larvae may simply opt to go for readily detectable signals. The notion that the larvae are attracted to reliable, familiar volatile signals even if it leads them to sub-optimal resources is further supported by the fact that previous experience with the odors enhances their attractiveness. But once they are on the plants they seem to avoid the volatiles and eat less when they detect high concentrations of them. We speculate that by doing so the larvae avoid the parts of the plant with up-regulated defenses, competition/cannibalism, and natural enemies that are attracted to the same volatiles.

An understanding of signals that are of importance for host plant foraging by caterpillars can be of use in the development of pest control strategies. In this context, current focus is on foraging of adults and this has found good use in "push-pull" strategies (Khan et al., 2000, 2008; Cook et al., 2007). Similarly, with the right combination of repellent and attractive volatiles, it may be possible to manipulate the foraging of caterpillar such that they are guided away from the crop and toward their demise on trap plants.

\section{ACKNOWLEDGMENTS}

We thank Matthias Erb for useful comments on the manuscript. Yves Borcard and several students of the University of Neuchâtel reared parasitoids, and Syngenta (Stein, Switzerland) provided $S$. littoralis eggs. This work received support by the Swiss National Science Foundation via the National Center of Competence in Research Plant Survival.

J. Chem. Ecol. 32, 1911-1924. doi: 10.1007/s10886-006-9117-9

potato beetle to herbivore-damaged plants during herbivory and after its termination. J. Chem. Ecol. 23, 1003-1023. doi: 10.1023/B:JOEC. $0000006385.70652 .5 \mathrm{e}$

Carlsson, M. A., Anderson, P., Hartlieb, E., and Hansson, B. S. (1999). Experience-dependent modification of orientational response to olfactory cues in larvae of Spodoptera littoralis. J. Chem. Ecol. 25, 2445-2454. doi: 10.1023/A:1020865922827

Carroll, M., Schmelz, E., and Teal, P. (2008). The attraction of Spodoptera frugiperda neonates to cowpea seedlings is mediated by volatiles induced by conspecific herbivory and the elicitor inceptin. J. Chem. Ecol. 34, 291-300. doi: 10.1007/s10886-007-9414-y

Carroll, M. J., Schmelz, E. A., Meagher, R. L., and Teal, P. E. A. (2006). Attraction of Spodoptera frugiperda damaged maize seedlings.
Castrejon, F., Virgen, A., and Rojas, J. C. (2009). Influence of chemical cues from host plants on the behavior of neonate Estigmene acrea larvae (Lepidoptera: Arctiidae). Environ. Entomol. 35, 700-707. doi: 10.1603/0046-225X-35.3.700

Chapman, J. W., Williams, T., Escribano, A., Caballero, P., Cave, R. D., and Goulson, D. (1999). Fitness consequences of cannibalism in the fall armyworm, Spodoptera frugiperda. Behav. Ecol. 10, 298-303. doi: 10.1093/beheco/ 10.3.298

Chapman, J. W., Williams, T., Martínez, A. M., Cisneros, J., Caballero, P., Cave, R. D., et al. (2000). Does cannibalism in Spodoptera frugiperda (Lepidoptera: Noctuidae) reduce the risk of predation? Behav. Ecol. Sociobiol. 48, 321-327. doi: 10.1007/s002650000237
Cook, S. M., Kahn, Z. R., and Pickett, J. A. (2007). The use of pushpull strategies in integrated pest management. Annu. Rev. Entomol. 52, 375-400. doi: 10.1146/annurev. ento.52.110405.091407

Crowe, M. L. (1995). The effect of season and group-size on survivorship and larval growth in Plagiodera versicolora. Ecol. Entomol. 20, 27-32. doi: 10.1111/j.13652311.1995.tb00425.x

D’Alessandro, M., and Turlings, T. C. J. (2005). In-situ modification of herbivore-induced plant odors: a novel approach to study the attractiveness of volatile organic compounds to parasitic wasps. Chem. Senses 30, 739-753. doi: 10.1093/chemse/bji066

D'Alessandro, M., and Turlings, T. C. J. (2006). Advances and challenges in the identification of volatiles that mediate interactions among plants and arthropods. 
Analyst 131, 24-32. doi: 10.1039/ b507589k

Degen, T., Dillmann, C., Marion-Poll, F., and Turlings, T. C. J. (2004). High genetic variability of herbivoreinduced volatile emission within a broad range of maize inbred lines. Plant Physiol. 135, 1928-1938. doi: 10.1104/pp.104.039891

de Groot, P., Grant, G., Poland, T., Scharbach, R., Buchan, L., Nott, R., et al. (2008). Electrophysiological response and attraction of emerald ash borer to green leaf volatiles (GLVs) emitted by host foliage. J. Chem. Ecol. 34, 1170-1179. doi: 10.1007/s10886008-9514-3

del Campo, M. L., Miles, C. I., Schroeder, F. C., Mueller, C., Booker, R., and Renwick, J. A. (2001). Host recognition by the tobacco hornworm is mediated by a host plant compound. Nature 411, 186-189. doi: 10.1038/35075559

De Moraes, C. M., Mescher, M. C., and Tumlinson, J. H. (2001). Caterpillar-induced nocturnal plant volatiles repel conspecific females. Nature 410, 577-580. doi: $10.1038 / 35069058$

Dicke, M., and Baldwin, I. T. (2010). The evolutionary context for herbivore-induced plant volatiles: beyond the "cry for help". Trends Plant Sci. 15, 167-175. doi: 10.1016/j.tplants.2009.12.002

Dicke, M., Sabelis, M. W., Takabayashi, J., Bruin, J., and Posthumus, M. A. (1990). Plant strategies of manipulating predatorprey interactions through allelochemicals: prospects for application in pest control. J. Chem. Ecol. 16, 3091-3118. doi: 10.1007/BF00979614

Fox, L. R. (1975). Cannibalism in natural populations. Annu. Rev. Ecol. Syst. 6, 87-106. doi: 10.1146/ annurev.es.06.110175.000511

Halitschke, R., Stenberg, J. A., Kessler, D., Kessler, A., and Baldwin, I. T. (2008). Shared signals_-alarm calls" from plants increase apparency to herbivores and their enemies in nature. Ecol. Lett. 11, 24-34. doi: 10.1111/j.1461-0248.2007.01123.x

Hansson, B. S., Larsson, M. C., and Leal, W. S. (1999). Green leaf volatile-detecting olfactory receptor neurones display very high sensitivity and specificity in a scarab beetle. Physiol. Entomol. 24, 121-126. doi: 10.1046/j.13653032.1999.00121.x

Hare, J. D. (2011). Ecological role of volatiles produced by plants in response to damage by herbivorous insects. Annu. Rev. Entomol.
56, 161-180. doi: 10.1146/annurevento-120709-144753

Heil, M. (2004). Direct defense or ecological costs: responses of herbivorous beetles to volatiles released by wild lima bean (Phaseolus lunatus). J. Chem. Ecol. 30, 1289-1295. doi: 10.1023/B:JOEC.0000030299. 59863.69

Heil, M. (2008). Indirect defence via tritrophic interactions. New Phytol. 178, 41-61. doi: 10.1111/j.14698137.2007.02330.x

Hoballah, M. E., and Turlings, T. C. J. (2005). The role of fresh versus old leaf damage in the attraction of parasitic wasps to herbivore-induced maize volatiles. J. Chem. Ecol. 31, 2003-2018. doi: 10.1007/s10886-005-6074-7

Huang, C.-H., Yan, F.-M., Byers, J. A., Wang, R.-J., and $\mathrm{Xu}, \mathrm{C} . \mathrm{-R}$. (2009). Volatiles induced by the larvae of the Asian corn borer (Ostrinia furnacalis) in maize plants affect behavior of conspecific larvae and female adults. Insect Sci. 16, 311-320. doi: 10.1111/j.17447917.2009.01257.x

Kakimoto, T., Fujisaki, K., and Miyatake, T. (2009). Egg laying preference, larval dispersion, and cannibalism in Helicoverpa armigera (Lepidoptera: Noctuidae). Ann. Entomol. Soc. Am. 96, 793-798. doi: 10.1603/0013-8746(2003)096[0793: ELPLDA]2.0.CO;2

Kalberer, N. M., Turlings, T. C. J., and Rahier, M. (2001). Attraction of a leaf beetle (Oreina cacaliae) to damaged host plants. J. Chem. Ecol. 27, 647-661. doi: 10.1023/A:1010389500009

Kessler, A., and Baldwin, I. T. (2001). Defensive function of herbivore-induced plant volatile emissions in nature. Science 291, 2141-2144. doi: 10.1126/science.291.5511.2141

Khan, Z. R., James, D. G., Midega, C. A. O., and Pickett, J. A. (2008). Chemical ecology and conservation biological control. Biol. Control 45, 210-224. doi: $\quad 10.1016 /$ j.biocontrol.2007. 11.009

Khan, Z. R., Pickett, J. A., van den Berg, J., Wadhams, L. J., and Woodcock, C. M. (2000). Exploiting chemical ecology and species diversity: stem borer and striga control for maize and sorghum in Africa. Pest Manage. Sci. 56, 957-962. doi: 10.10 02/1526-4998(200011)56:11<957:: AID-PS236>3.0.CO;2-T

Landolt, P. J. (1993). Effects of host plant leaf damage on cabbagelooper moth attraction and oviposition. Entomol. Exp. Appl.
67, 79-85. doi: 10.1111/j.15707458.1993.tb01654.x

Landolt, P. J., Brumley, J. A. Smithhisler, C. L., Biddick, L. L., and Hofstetter, R. W. (2000). Apple fruit infested with codling moth are more attractive to neonate codling moth larvae and possess increased amounts of (E, E)-alpha-farnesene. J. Chem. Ecol. 26, 1685-1699. doi: 10.1023/A:1005595014589

Landolt, P. J., Tumlinson, J. H., and Alborn, D. H. (1999). Attraction of Colorado potato beetle (Coleoptera: Chrysomelidae) to damaged and chemically induced potato plants. Environ. Entomol. 28, 973-978.

Müller, C., and Hilker, M. (2000). The effect of a green leaf volatile on host plant finding by larvae of a herbivorous insect. Naturwissenschaften 87, 216-219. doi: 10.1007/s001140050706

Paré, P. W., and Tumlinson, J. H. (1999). Plant volatiles as a defense against insect herbivores. Plant Physiol. 121, 325-332. doi: 10.1104/pp.121.2.325

Piesik, D., Rochat, D., van der Pers, J., and Marion-Poll, F. (2009). Pulsed odors from maize or spinach elicit orientation in European corn borer neonate larvae. J. Chem. Ecol. 35, 1032-1042. doi: 10.1007/s10886009-9676-7

R Development Core Team. (2009). $R$ : A Language and Environment for Statistical Computing, 2.9.1 Edn. Vienna: R Foundation for Statistical Computing. Available online at: http://www.R-project.org

Ricard, I., and Davison, A. C. (2007). Statistical inference for olfactometer data. J. Roy. Stat. Soc. C-App 56, 479-492. doi: 10.1111/j.14679876.2007.00588.x

Richardson, M. L., Mitchell, R. F., Reagel, P. F., and Hanks, L. M. (2009). Causes and consequences of cannibalism in noncarnivorous insects. Annu. Rev. Entomol. 55, 39-53. doi: 10.1146/annurev-ento112408-085314

Rostas, M., and Hilker, M. (2002). Feeding damage by larvae of the mustard leaf beetle deters conspecific females from oviposition and feeding. Entomol. Exp. Appl. 103, 267-277. doi: 10.1046/j.15707458.2002.00984.x

Shiojiri, K., Ozawa, R., and Takabayashi, J. (2006). Plant volatiles, rather than light, determine the nocturnal behavior of a caterpillar. PLoS Biol. 4:e164. doi: 10.1371/journal.pbio.0040164

Tamò, C., Ricard, I., Held, M., Davison, A. C., and Turlings, T. C. J. (2006)
A comparison of naïve and conditioned responses of three generalist endoparasitoids of lepidopteran larvae to host-induced plant odours. Anim. Biol. 56, 205-220. doi: $10.1163 / 157075606777304177$

Ton, J., D'Alessandro, M., Jourdie, V., Jakab, G., Karlen, D., Held, M., et al. (2007). Priming by airborne signals boosts direct and indirect resistance in maize. Plant J. 49, 16-26. doi: $10.1111 /$ j.1365-313X.2006 02935.x

Turlings, T. C. J., Davison, A. C., and Tamò, C. (2004). A six-arm olfactometer permitting simultaneous observation of insect attraction and odour trapping. Physiol. Entomol. 29, 45-55. doi: $\quad 10.1111 / \mathrm{j} .1365-3032.2004$. 0362. $\mathrm{x}$

Turlings, T. C. J., Lengwiler, U. B., Bernasconi, M. L., and Wechsler, D. (1998). Timing of induced volatile emissions in maize seedlings. Planta 207, 146-152. doi: 10.1007/s004250050466

Turlings, T. C. J., Tumlinson, J. H., and Lewis, W. J. (1990). Exploitation of herbivore-induced plant odors by host-seeking parasitic wasps. Science 250, 1251-1253. doi: 10.1126/science. 250.4985 .1251

Turlings, T. C. J., and Wäckers, F. (2004). Recruitment of predator and parasitoid by herbivore-injured plants. $A d v$. Insect Chem. Ecol. 2, 21-75. doi: 10.1017/CBO9780511542664.003

Vet, L. E. M., and Dicke, M. (1992). Ecology of infochemical use by natural enemies in a tritrophic context. Annu. Rev. Entomol. 37, 141-172. doi: 10.1146/annurev.en.37.010192. 001041

von Mérey, G., Veyrat, N., Mahuku, G., Valdez, R. L., Turlings, T. C. J., and D'Alessandro, M. (2011). Dispensing synthetic green leaf volatiles in maize fields increases the release of sesquiterpenes by the plants, but has little effect on the attraction of pest and beneficial insects. Phytochemistry 72, 1838-1847. doi: 10.1016/j.phytochem.2011.04.022

Whitman, D. W., and Eller, F. J. (1990). Parasitic wasps orient to green leaf volatiles. Chemoecology 1, 69-76. doi: 10.1007/BF01325231

Yoneya, K., Ozawa, R., and Takabayashi, J. (2010). Specialist leaf beetle larvae use volatiles from willow leaves infested by conspecifics for reaggregation in a tree. J. Chem. Ecol. 36, 671-679. doi: 10.1007/s10886-010-9808-0

Zalucki, M. P., Clarke, A. R., and Malcolm, S. B. (2002). Ecology 
and behavior of first instar larval Lepidoptera. Аnnu. Rev. Entomol. 47, 361-393. doi: 10.1146/annurev. ento.47.091201.145220

Conflict of Interest Statement: The authors declare that the research was conducted in the absence of any commercial or financial relationships that could be construed as a potential conflict of interest.

Received: 28 February 2013; accepted: 02 June 2013; published online: 28 June 2013.

Citation: von Mérey GE, Veyrat N, D'Alessandro $M$ and Turlings TCJ (2013) Herbivore-induced maize leaf volatiles affect attraction and feeding behavior of Spodoptera littoralis caterpillars. Front. Plant Sci. 4:209. doi: 10.3389/fpls.2013.00209

This article was submitted to Frontiers in Plant-Microbe Interaction, a specialty of Frontiers in Plant Science.

Copyright (c) 2013 von Mérey, Veyrat, D'Alessandro and Turlings. This is an open-access article distributed under the terms of the Creative Commons Attribution License, which permits use, distribution and reproduction in other forums, provided the original authors and source are credited and subject to any copyright notices concerning any third-party graphics etc. 